\title{
A História do Conceito Onanismo na Psiquiatria dos Séculos XVIII e XIX
}

\author{
(Parte 1) \\ Anna Rita Maciel Simião* \\ Universidade Federal de Juiz de Fora - UFJF, Juiz de Fora, MG, Brasil \\ ORCID: http://orcid.org/0000-0001-6752-6750 \\ Richard Theisen Simanke** \\ Universidade Federal de Juiz de Fora - UFJF, Juiz de Fora, MG, Brasil \\ ORCID: http://orcid.org/0000-0002-6405-8776
}

\begin{abstract}
RESUMO
O presente estudo pretende retomar a história do conceito de masturbação com foco em como ele se desdobrou de um conceito fundamental para a medicina geral para, posteriormente, um conceito importante no contexto dos primeiros estudos médicos e psicológicos sobre sexualidade humana, principalmente os estudos das perversões sexuais, principal campo explorado no final do século XIX e início do século XX. O artigo, primeira parte de um estudo divido em duas partes, pretende contemplar como se deu a ascensão e decadência dos estudos sobre a masturbação na medicina, partindo do surgimento do conceito onanismo e seguindo por meados do século XIX, quando ambos os conceitos se tornaram importantes dentro dos estudos das perversões sexuais. O ponto de desfecho é a obra de Albert Moll, famoso psiquiatra alemão e um dos pioneiros entre os teóricos da sexualidade humana a questionar abertamente a relevância do conceito de masturbação dentro das teorias da sexualidade.
\end{abstract}

Palavras-chave: história da psicologia, história da psiquiatria, onanismo, masturbação, psicopatia sexual, Albert Moll.

\section{History of the Concept Onanism in Psychiatry in the 18th and 19th}

\section{centuries (Part 1)}

\begin{abstract}
This study intends to resume the history of the concept of masturbation with the focus on how it unfolded from a fundamental concept for general medicine to a later important concept in the context of the first medical and psychological studies of human sexuality, especially studies of sexual perversions, the main field explored in the late 19th and early 20th centuries. The article, first part of a two-part study, intends to contemplate how the rise and decline of studies on masturbation in medicine took place, starting from the emergence of the concept of onanism and following through mid XIX century, when both concepts became important
\end{abstract}

ISSN $1808-4281$

v. 21

ก. 2


within the study of sexual perversions. The final point of this article is the work of Albert Moll, a famous German psychiatrist and one of the pioneers among human sexuality theorists to openly question the relevance of the concept of masturbation within the theories of sexuality.

Keywords: history of psychology, history of psychiatry, onanism, masturbation, sexual psychopathy, Albert Moll.

\section{Historia del Concepto Onanismo en La Psiquiatría de los Siglos XVIII y}

\section{XIX (Parte 1)}

\section{RESUMEN}

Este estudio pretende retomar la historia del concepto de masturbación con el foco en cómo se desdobló desde un concepto fundamental para la medicina general para, posteriormente, un concepto importante en el contexto de los primeros estudios médicos y psicológicos de la sexualidad humana, principalmente estudios de perversiones sexuales, el campo principal explorado a finales del siglo XIX y principios del XX. El artículo, primera parte de un estudio dividido en dos, pretende contemplar cómo se produjo el auge y declive de los estudios sobre la masturbación en medicina, a partir del surgimiento del concepto de onanismo y siguiendo a mediados del siglo XIX, cuando ambos conceptos son importantes en el estudio de las perversiones sexuales. El punto final es la obra de Albert Moll, un famoso psiquiatra alemán y uno de los pioneros entre los teóricos de la sexualidad humana que cuestiona abiertamente la relevancia del concepto de masturbación dentro de las teorías de la sexualidad.

Palabras clave: historia de la psicología, historia de la psiquiatría, onanismo, masturbación, psicopatía sexual, Albert Moll.

A retomada da história do conceito masturbação - e seu correlato, sinônimo e derivado onanismo - se faz importante parte das muitas discussões que a história da psiquiatria e a história da psicologia possibilitam.

O conceito de masturbação desfrutou de um lugar bem peculiar ao longo dos séculos dentro da história da Medicina, sendo que as discussões sobre o termo extrapolaram a medicina geral e perpassaram a história de áreas derivadas, tais como a Psiquiatria e a Psicologia. Em um percurso que pode ser traçado desde escritos médicos antigos até a psicanálise de Sigmund Freud e além, o conceito de onanismo assumiu, por um longo tempo, um papel central como a razão de adoecimentos do corpo, da mente e da sexualidade. Posteriormente, no início do século XX, através de derivações do conceito - entre elas a ideia de autoerotismo ${ }^{1}$ - que podiam ser traçadas das ideias anteriores sobre onanismo, o termo 
resistiu, mas com mais enfoque na sua faceta de ato físico com reverberações psicológicas para a constituição da sexualidade dos sujeitos e, em última instância, de suas próprias personalidades.

O artigo irá discutir a primeira parte desse percurso, dos escritos médicos do século XVIII até a figura do psiquiatra alemão Albert Moll (1862-1939), um dos pioneiros entre os teóricos da sexualidade humana a questionar abertamente a relevância do conceito de masturbação dentro das teorias psiquiátricas e psicológicas da sexualidade.

Antes de iniciar a argumentação do artigo, é necessário atentar para o fato de que o termo masturbação aparece nas obras clássicas a serem tratadas aqui em conjunto com o termo onanismo. O termo mais comum durante o final do século XVIII e o século XIX era onanismo. Esse conceito surgiu em 1716, data mais provável de publicação do livro Onania: or, the heinous sin of self-pollution and all its frightful consequences, de autor desconhecido ${ }^{2}$. Anônimo (1756) fazia alusão ao personagem bíblico Onã, que foi castigado por Deus por se recusar a ter filhos com Tamar, viúva de seu irmão mais velho, conforme era o costume pelas leis da época. O autor do livro Onania escolheu Onã para nomear o conceito uma vez que o personagem interrompia o coito e finalizava sozinho o encontro sexual ejaculando fora do corpo da mulher, desperdiçando, portanto, o sêmen.

Conceitualmente, o termo onanismo carregava o mesmo sentido geral de masturbação: o ato de autogratificação sexual, mas fazia alusão à conotação de pecado que o autor do livro Onania pretendia passar em sua obra. De acordo com o E. Paul, tradutor oficial de língua inglesa das obras do psiquiatra alemão Albert Moll, masturbação era uma palavra de origem etimológica desconhecida, derivada de manustrupation, do latim manu (mão) e stupratio (desonrar), ou do latim masturbor, forma de turbor (transe) (Moll, 1908), um termo que destacava mais a maneira da autogratificação ${ }^{3}$.

Apesar dessas diferenças, na maioria dos textos sobre sexologia do século XIX e início do $\mathrm{XX}$, os dois termos eram usados como sinônimos de autogratificação sexual de maneira mecânica não identificada - ou seja, os autores muitas vezes não identificavam a maneira pela qual o paciente se autogratificava. Posteriormente, já em meados do século XX, os seus sentidos e significados voltaram a se diferenciar. Por focar as argumentações no século XIX e nos séculos anteriores, este trabalho também usará masturbação e onanismo como sinônimos. 


\section{Teorias da Sexualidade do Século XVIII}

Hall (1992), Hunt (1998), Hare (1962), Stolberg (2000) e Laqueur (2003) apontam que a história da percepção da masturbação é bastante conhecida entre os historiadores: depois de séculos sendo considerado como um assunto secundário nas apreciações médicas desde a antiguidade, em 1716, com a publicação do já citado Onania e, posteriormente, da tese de Samuel Tissot, L'onanisme, em 1756, a masturbação passou a representar o centro de argumentos sobre adoecimentos mentais e físicos. Para aprofundar no tema de como a masturbação ganhou esse status, é necessário, primeiramente, explicitar o contexto histórico no qual os estudos sobre a sexualidade estavam inseridos.

Garlick (2011, p. 308) aponta que, do ponto de vista dos historiadores da sexualidade, o motivo pelo qual o estudo dos malefícios causados pelas práticas sexuais desviantes passou a ter, nos séculos XVIII e XIX, um foco até então inédito geralmente girava em torno de fatores diversos: os interesses de médicos em usar a questão sexual para promover a sua posição profissional; o declínio da autoridade religiosa em favor de apelos à ciência e à natureza (sem que de fato os preceitos religiosos fossem completamente abandonados) e a preocupação sobre o desenvolvimento do individualismo e das atividades sexuais improdutivas - no sentido de não resultarem em novos indivíduos aptos para o trabalho - no contexto de uma sociedade que buscava a expansão de seus componentes enquanto ascendia ao capitalismo.

Laqueur (2003, p. 210) aponta que, para esse novo contexto social, a masturbação seria especialmente problemática, pois seria uma atividade secreta, sem nenhuma troca social ou necessidade de um laço social produtivo; não teria um objeto de desejo definido; poderia se tornar excessiva com muita facilidade; não necessitaria de testemunhas e, principalmente, seria um produto da imaginação. Como resultado disso, a masturbação colocaria em destaque a enorme capacidade imaginativa das imoralidades que poderiam estar contidas nos desejos ocultos de todos os seres humanos.

Dentro desse contexto cultural, o cenário científico dos séculos XVIII e XIX contava com uma ideia recorrente nos textos de muitos autores de teorias médicas e psiquiátricas da época, que ganhou grande força com a teoria darwinista: a de que o instinto sexual seria uma necessidade fundamental dos seres. Logo, ele estaria presente na constituição das espécies, impeliria o organismo através de processos físicos e mentais para que fosse satisfeito no ato do coito e cumpriria o papel de preservação dos genes e das espécies através da prole. Quando as atividades sexuais se repetissem com muita frequência e com gasto de líquido seminal, 
causariam desordens nos processos físicos e mentais naturais do organismo e, consequentemente, entraves para que o instinto sexual cumprisse sua finalidade natural: ser satisfeito através do coito com um par de sexo oposto para gerar prole. Esses entraves seriam causadores de adoecimentos físicos e psíquicos e da impossibilidade de, em longo prazo, o corpo ser apto para a vida sexual (Simião, 2019).

Autores da antiguidade e anteriores ao século XVIII já traziam em seus textos médicos os males físicos que o engajamento exacerbado em qualquer atividade sexual poderia causar, mas sem nenhuma teorização aprofundada sobre quais seriam de fato esses malefícios ou uma definição do que seria um engajamento exacerbado. Por isso é provável que concepções nessa linha de pensamento tivessem uma origem anterior aos séculos XVIII e XIX e à apreciação darwinista, desde os escritos de médicos da antiguidade e de médicos iluministas, tais como Hipócrates e Boerhaave (Hare, 1962). A masturbação, até aquele momento, ainda tinha um papel muito diminuído nessas apreciações, normalmente indiferenciada de outras atividades sexuais sem fins de procriação, contando com alguns trabalhos de tradição moralistateológica dedicados exclusivamente ao conceito (Stolberg, 2000).

Essas noções sobre engajamento sexual exacerbado e, principalmente, sobre atividades sexuais que escapassem da finalidade do instinto sexual - ou atividades sexuais "desviantes", "antinaturais" e "improdutivas" - foram largamente amplificadas ao longo dos séculos, com interesse crescente na masturbação no século XVII e extremo foco a partir do século XVIII, dos primeiros estudos de tradição moralista-teológica até a Onania. E depois, principalmente, dentro dos estudos psiquiátricos - uma ciência parte da medicina e relativamente nova.

\section{A Onania (1716) e O onanismo (1756)}

Tido como o livro que inaugurou o destaque para o interesse sobre os estudos da masturbação e que cunhou o termo onanismo, a obra Onania representa um ponto interessante na história do conceito. Apesar de criticada (Tissot, 1769) pelo tom fortemente ensaístico e religioso, pela estrutura tida como simplória e por não conter praticamente nenhuma citação a textos de outros médicos, a obra conseguiu influenciar os estudos da sexualidade durante um século e meio. As razões para isso precisam ser avaliadas com cuidado.

Em relação à estrutura, o livro (Anônimo, 1756) consiste em duas partes. A introdução e a primeira parte buscam explicar o conceito onanismo e as razões para que esse ato sexual fosse um pecado mais nocivo que outros atos sexuais não naturais. Essa parte consistia no 
maior ponto de crítica, por sua base teórica ser formada basicamente por escrituras bíblicas, em uma longa discussão sobre as vontades de Deus em relação à sexualidade humana.

Para Anônimo (1756), o onanismo seria a prática antinatural pela qual as pessoas, de qualquer um dos sexos e mesmo sem nenhum desvio intelectual ou moral, corromperiam seus próprios corpos em ato sexuais sem afiliação com outros, "uma vez que, cedendo à imaginação suja, eles se esforçam para imitar e procurar em si mesmos aquela sensação que Deus concedeu para gratificar a troca carnal de dois sexos para a continuação de nossa espécie" (Anônimo, 1756, p. 2, tradução nossa). Os outros pecados sexuais, tais como adultério e fornicação, poderiam ser encarados como resultado da fragilidade humana perante a tentação ou como resultado de uma fraqueza perante a Natureza, a saber, o desejo natural, concedido pelo divino e de raízes irracionais, que os seres teriam pela satisfação do instinto sexual com um par. A masturbação, porém, seria um pecado contra a própria Natureza porque prejudicaria a ação sexual que deveria ser investida em outra pessoa para a propagação da espécie.

A parte seguinte - maior porção do livro - corresponde às cartas que Anônimo teria recebido de pacientes que teriam praticado o onanismo durante longos anos e agora estariam conscientes de todo o problema que a prática teria causado em suas vidas. Os relatos são muito numerosos para serem citados integralmente neste artigo; assim, cabe assinalar que, a partir deles, o autor apresenta um conjunto vasto de patologias que afligiriam os onanistas. Essas aflições poderiam ser de ordem física, que davam conta de problemas clínicos de diversas ordens tais como: problemas de pele, crescimento anormal de pelos pelo corpo, impotência sexual e esterilidade, entre outros; ou ainda de ordem espiritual, que indicariam maior gravidade consequencial do ato, podendo acometer a pessoa com melancolias, sentimento de culpa, tentativas de suicídio, entre outras, e até mesmo casos de insanidade leve, se relacionadas com as aflições de ordem física.

Muito pouco sobre outras observações médicas acerca desses temas ou de teorias que os discutissem é referenciado no livro. Os relatos ocupam a maior parte da obra e são apontados pelo autor como "provas cientificas", pois seu grande número, as diferenças sociais e particulares entre as pessoas e as repetições das aflições seriam evidências suficientes de que o ato do onanismo seria o causador daqueles males (Anônimo, 1756) ${ }^{4}$.

Devido ao tom ensaístico da Onania, Hunt (1998, p. 576-577) discute brevemente a razão pela qual a maioria da opinião médica da época teria reverberado argumentações a partir de publicações ainda carregadas de ideias não cientificas, ou seja, publicações quasemédicas. O autor lembra que a Medicina, como uma disciplina acadêmica, procurou 
reconhecimento e expansão de sua jurisdição enquanto teoria durante o século XIX. A consolidação do que seriam teorias baseadas em aspectos menos científicos permaneceu sem limites bem definidos durante boa parte do século XIX e início do século XX.

É provável que o possível sucesso comercial da obra e suas inúmeras edições - como apontam Hare (1962), Hall (1992) e Stolberg (2000) - tenha chamado a atenção dos médicos da época para a criação do conceito onanismo, mesmo que médicos renomados não estivessem dispostos a citar nominalmente o livro.

É possível ainda, a partir das leituras do corpo de obras que compõe a bibliografia deste artigo, fazer - ainda que de maneira um tanto especulativa - algumas contribuições acerca das razões para a influência de um texto como a Onania na medicina e áreas adjacentes.

Além do período histórico que favorecia o relaxamento para publicações quasemédicas como a Onania, a ideia de Anônimo, apesar de justificada por textos religiosos, não perdia totalmente a relação com as ideias mais recorrentes da medicina, tais como a finalidade reprodutiva do sexo ou os males do engajamento exacerbado. A própria justificativa em si era bem clara e por vezes evocava alguma base biológica entre as citações da Bíblia.

Como ponto mais relevante, apesar do conteúdo teórico do texto da Onania ser visto como problemático no sentido de não oferecer grandes discussões, relatos de caso e argumentações de outros autores sobre o tema - como era o costume em textos de médicos respeitados -, a segunda parte não era totalmente distante dos textos psiquiátricos iniciais sobre a sexualidade. $\mathrm{Na}$ maioria desses textos, relatos eram pontos de extrema importância para ilustrar e definir as manifestações clínicas de uma doença. Grandes compilados de diversos casos médicos sobre o mesmo tema, demonstrando uma recorrência dos sintomas, eram vistos como importantes dados de observação empírica sobre uma patologia.

Esses pontos representavam uma espécie de avanço do texto inicial sobre onanismo em comparação aos textos totalmente situados na tradição moralista-teológica apontada por Stolberg (2000). A criação do termo onanismo e as evidências clínicas de seu malefício não estavam de todo alheias ao campo médico, apenas a base de explicação do termo extrapolava o rigor da medicina.

Ressalta-se que a influência da Onania na medicina foi "silenciosa", pois, apesar das ideias terem sido descritas primeiro nela, a obra foi citada apenas sete vezes entre a provável data de sua publicação em 1716 até o ano de publicação da monografia de Tissot (Hare 1962). Contudo, a ideia de aflições que seriam causadas pela prática onanista não encontrou nenhuma crítica influente ${ }^{5}$, nem mesmo entre médicos como o suíço Samuel Auguste Tissot 
(1728-1797), que, ao contrário de autores anteriores que falavam sobre sexualidade desviante, era um renomado professor e conselheiro do Vaticano. Na época da publicação de sua tese, Tissot desfrutava de grande credibilidade entre seus colegas europeus. Para construir sua própria monografia sobre o onanismo, Tissot adotou o termo, renegou toda a parte sobre pecados e explicações de problemas divinos da Onania, replicou a ocorrência de aflições e tomou como ponto central explicar as razões estritamente biológicas pelas quais o onanismo causaria essas aflições.

Na obra de Tissot, o primeiro capítulo se preocupa em traçar as publicações médicas e filosóficas que abordavam temas que poderiam relacionar o onanismo às doenças físicas e mentais. Começando pela teoria dos humores, Tissot apresenta um compilado de casos de outros autores e teorias sobre relações sexuais para construir suas argumentações. Também reapresenta as doenças que afetavam a totalidade do corpo e de suas funções, presentes no livro Onania (Tissot, 1769, p. 26-34) em males de diversas ordens, e acrescenta mais algumas manifestações que ainda não tinham sido relatadas.

A argumentação de Tissot oferece o argumento mais sólido, entre as obras aqui abordadas, sobre a importância do fluído seminal para o corpo humano, base traçada desde os escritos dos médicos da antiguidade e que representava um ponto chave em sua teoria sobre a causa dos males do onanismo.

A natureza teria constituído os corpos humanos com uma quantidade de líquido seminal para ser liberada durante o êxtase sexual. Essa quantidade, após a ejaculação, seria reposta pelo próprio organismo, deixando o sujeito no estado natural até o momento de outra relação sexual. O líquido seminal seria importante para a força vital e teria relação com os outros humores do homem, incluindo o sangue, que circularia por todos os órgãos do corpo. Atividades sexuais causariam uma perda de sêmen. A perda de sêmen, de maneira constante e desenfreada, faria com que, eventualmente, o corpo enfraquecesse a capacidade dessa reposição, afetando a força geral e causando consequências físicas, mentais e sexuais terríveis (Tissot, 1769). Tissot, em sua introdução (1769), argumenta que existiria uma diferença entre a perda do fluído seminal em atividades sexuais naturais e antinaturais. Embora a descarga constante fizesse mal em ambos os casos, a perda pelas causas antinaturais seria muito mais danosa, pois sendo o coito uma necessidade humana - de mesma ordem que o sono e a fome - seria benéfica uma descarga de fluido seminal para que o ato sexual pudesse ser satisfeito. Atos que não satisfizessem a necessidade primordial seriam atos de perda de sêmen sem o propósito da natureza (Tissot, 1769). 
Tissot, ao longo de sua obra, varia bastante no motivo pelo qual a masturbação seria um vício mais danoso dentre todas as manifestações antinaturais da necessidade sexual. Suas teorias vão desde as consequências físicas do sentimento de remorso e a relação mórbida de exclusividade entre a excitação dos órgãos e o ato do onanismo até o fato da masturbação ser mais comum em pessoas jovens em momento de formação de caráter, podendo facilmente se converter em hábito (Stolberg, 2000).

A boa reputação de Tissot conferiu a seriedade médica - ausente na Onania e necessária para a Medicina - para que os argumentos da masturbação como causadora de doenças ganhassem mais visibilidade e aceitação pela comunidade intelectual. De fato, o trabalho de Tissot, em termos teóricos, contrasta bastante com o tom da Onania. Ainda que, alguns anos mais tarde, Tissot tenha sido criticado - principalmente por autores de teorias da sexualidade como Albert Moll e o britânico Havelock Ellis (1859-1939) - por ter deixado que suas crenças religiosas obnubilassem seu julgamento médico na análise do tema do onanismo (mesma critica dispensada por outros ao autor da Onania), o corpo da obra apresenta teorias e explicações bem variadas, apoiando suas argumentações em estudos de casos próprios e de outros autores, que aproximam ainda mais sua estruturação teórica de textos científicos psiquiátricos posteriores, principalmente os dos manuais da sexualidade no final do século XIX.

Entre a publicação do livro Onania e a monografia de Tissot, foram lançados apenas alguns poucos trabalhos de psiquiatras renomados citando a masturbação como principal causadora de doenças. Depois de 1756, contudo, o número de estudos aumentou vertiginosamente (Hare, 1962, p. 4).

A ideia da masturbação como causa de doenças físicas e mentais começou a ser dissecada como um fato científico, chegando até Esquirol (1772-1840), que, em seu Des Maladies Mentales, escreveu que a masturbação parecia ser uma das causas da mania, da demência e da demência senil. Outros grandes nomes da psiquiatria da época, como Guislain (1797-1860), Greisinger (1817-1868) e Flemming (1843-1905), também citaram, em vários de seus textos, os males da masturbação. Em 1863, David Skae (1814-1873) estabelece o princípio de que os transtornos mentais deveriam ser classificados de acordo com sua história natural e não pelos sintomas associados. Nessa classificação, idiotia ${ }^{6}$ e epilepsia seriam os dois primeiros grupos naturais. A terceira família natural seria a dos masturbadores. Skae, então, cunhou o termo insanidade masturbatória, com bastante alcance teórico em países de língua inglesa (Hare, 1962). 
Instaurava-se, assim, entre os escritos científicos da época, um verdadeiro "ataque" à masturbação, que persistiria de 1716 até por mais de 150 anos, quando, como efeito, quanto mais médicos se debruçavam em estudar, apontar e observar os casos em que a masturbação poderia causar as doenças descritas nas décadas anteriores, mais hipóteses de que a masturbação poderia ser não a causa, mas um dos muitos sintomas das doenças, começavam a tomar forma (Hunt, 1998).

\section{Onanismo e as Teorias da Sexualidade}

Hare (1962, p. 13) aponta quatro razões pelas quais a ideia da masturbação causadora de insanidades e outras aflições físicas terríveis foi sendo gradativamente abandonada na medicina geral: (1) a primeira é que o onanismo seria, na verdade, uma complicação ou até um sintoma, não a causa. Essa ideia sempre existiu, mas nunca tinha sido motivo de uma apreciação mais longa. O sucesso de teorias - como a frenologia de Gall - que atestavam abertamente o fato teria tornado impossível que psiquiatras de renome como Kraeplin (18561926) e Guislain continuassem sem abordá-lo; (2) a segunda, e mais importante, é que os autores - poucos, durante muito tempo - continuavam a afirmar que a masturbação era comum em pessoas saudáveis. Suas vozes foram se amplificando a partir do momento em que a primeira razão foi sendo mais elaborada; (3) a incapacidade de se ter certeza, somente a partir dos relatos de alguns pacientes, de que, de fato, a masturbação era tão frequente como relatado; e, por fim, (4) a falta de uma explicação fisiológica e decisiva do porquê a masturbação seria mais danosa que outras atividades sexuais para a vida mental.

Todo esse quadro contribuiu para que, entre os anos de 1895 e 1900, a visão de que a masturbação seria a causadora de doenças mentais e físicas caísse vertiginosamente. Porém, a ideia da masturbação como um malefício esteve, até o fim do século XIX, longe de ser abandonada. A ideia permaneceu, mas agora fazendo referência à masturbação como causa de desordens e neurastenias neuróticas e sexuais (Hare, 1962).

Nesse contexto, os famosos trabalhos de Henry Maudsley (1835-1918) merecem um olhar mais apurado. Maudsley foi um autor muito influente para os sexologistas do final do século XIX, apesar de ele mesmo não ter dedicado sua obra psiquiátrica exclusivamente às teorias da sexualidade (Simião, 2019).

Em seu livro mais referenciado por seus contemporâneos, Pathology of Mind, Maudsley (1867) apresenta a masturbação como causa de insanidades sexuais, neuroses e doenças relacionadas à sexualidade, principalmente quando ligada às degenerações mentais ${ }^{7}$. 
Maudsley, assim como outros estudiosos da medicina, eventualmente - como perceptível na edição do Pathology of Mind de 1895 - cedeu em suas visões iniciais sobre a insanidade masturbatória e ligou a masturbação a sintomas das neurastenias sexuais ou perversões do instinto genital.

Em 1844, o livro Psychopathia Sexualis, de autoria de Heinrich Kaan (1816-1893), se tornou o primeiro dos manuais a explorar detalhadamente o conceito de psicopatia sexual (termo derivado e por muitas vezes sinônimo de perversão sexual ou perversão do instinto genital) como uma classe que englobava diversos tipos de insanidades e neurastenias morais e sexuais. Kaan (1844) argumenta que, de todos os instintos de função biológica humana, o instinto sexual seria o que mais teria relação com outros componentes físicos e mentais do organismo, por isso, mais do que todos os outros instintos, seria passível de apresentar variados desvios na norma (em relação a se afastar de sua finalidade de procriação) e na qualidade (em relação a ter como alvo outros objetos além de um par do sexo oposto). Essas múltiplas manifestações, em suas facetas mais perigosas, se apresentariam como constantes para substituir o coito e a procriação. As manifestações mais perigosas seriam: a masturbação; a adoração por crianças ${ }^{8}$; o amor lésbico; a necrofilia; a pederastia; a prática de coito com animais.

Kaan (1844, p. 46) acredita que a razão pela qual os seres humanos (mesmo que estudados e com pleno conhecimento das leis) poderiam sucumbir a atos condenáveis como os descritos acima deveria ser procurada nos próprios homens, na forma de uma fantasia sexual doentia e prematura que causaria um desejo anormal e que criaria meios para ser sexualmente saciada. Essa fantasia poderia ser denominada como fantasia mórbida. Sua provável causa seria as degenerações mentais, morais e físicas do organismo das pessoas afetadas, unidas aos maus hábitos e condições sociais. Kaan enfatiza sistematicamente ao longo de seu livro o caso do onanismo, o mau hábito primordial a agravar as psicopatias sexuais.

Em todas essas perversões sexuais, no momento que o instinto sexual fosse acionado pelo processo biológico para buscar a satisfação, prevaleceria a fantasia morbidamente excitada que ofuscaria o raciocínio e os bons costumes aprendidos: "Assim a fantasia prepara o caminho em todas as aberrações do impulso sexual, e por ela [a fantasia] ele é realizado contra as leis da Natureza.” (Kaan, 1844 p. 47, tradução nossa).

Em 1886, o médico austríaco Richard von Krafft-Ebing (1840-1902) lançou sua própria Psychopathia Sexualis, sem menção ao trabalho de Kaan. Sua boa reputação como psiquiatra fez com que o livro alcançasse fama mundial entre seus contemporâneos, 
eclipsando o livro de Kaan lançado décadas antes. Para Krafft-Ebing (1894), as neuroses sexuais parestésicas corresponderiam às psicopatias do instinto sexual, às neurastenias sexuais ou às perversões do instinto sexual. $\mathrm{O}$ sujeito teria a excitabilidade das funções sexuais e das práticas sexuais completamente dependente de estímulos irregulares. Nas neuroses sexuais parestésicas, o próprio colorido emocional sobre as ideias sexuais seria pervertido em sua natureza. As ideias sexuais que em pessoas normais causariam desgosto ou nojo provocariam, nas pessoas acometidas por essas afecções, emoções incontroláveis, prazerosas e excitantes. A causa dessa inversão nas emoções que as ideias sexuais deveriam despertar poderia decorrer da degeneração mental e de degenerações físicas associadas à inibição mental das sensações de nojo e desprazer perante o estímulo inadequado. Tanto o componente social quanto os hábitos teriam parte fundamental na causa da perversão. A ocorrência e o aprofundamento desses quadros mórbidos seria mantida pela prática irrestrita do hábito do onanismo. Como era frequente que o onanismo persistisse, as degenerações da perversão eram constantemente alimentadas pelos males que a prática da masturbação causava.

Ressalta-se aqui que a Psychopathia Sexualis de Krafft-Ebing representou um marco para os estudos da sexualidade desviante no século XIX. De acordo com Weeks (1985, p. 67), Kraft-Ebing, ao lado de Darwin, se configura no segundo momento principal e decisivo para a emergência dos discursos científicos sobre a sexualidade humana.

A influência exercida por Krafft-Ebing dentro dos estudos da sexualidade naquele momento representava um ponto muito prolifico. Suas ideias foram replicadas por seus contemporâneos e muitas delas - principalmente as categorias de psicopatias sexuais criadas por ele, tais como sadismo, masoquismo, zoofilia, entre outras - perduram até hoje nos estudos da sexologia e no imaginário social sobre a sexualidade humana. E ele se manteve por longos anos enfático na masturbação como o mau hábito crucial que agravaria e até mesmo ajudaria a causar o complexo desenvolvimento das perversões em um indivíduo. Em seus muitos relatos de casos em diversas obras, o autor ressaltava o histórico de onanismo nos pacientes.

Algumas razões para que a masturbação ocupasse esse lugar na teoria de Krafft-Ebing podem ser discutidas. A ideia de comportamentos sexuais que desviassem da forma natural identificada era conhecida na literatura e na literatura médica desde muito antes do século XIX. Até que a ideia das psicopatias sexuais tomasse forma, dois fatores eram importantes. Primeiro, a ideia sobre o desperdício de líquido seminal em atividades sexuais intensas e repetitivas levar ao adoecimento do organismo. $\mathrm{Na}$ verdade, o próprio conceito de neurastenia, apresentado por Beard (1869), parte de uma ideia similar. A neurastenia, ou 
exaustão nervosa, seria a condição hereditária e mórbida de fraqueza geral e falta de energia nervosa, por descargas corporais, cuja sintomatologia incluía perturbações físicas, mentais, sexuais e neuropsicológicas. A ideia de que a exaustão nervosa fazia mal ao organismo e a ideia de desperdício do líquido seminal como uma causa de exaustão do organismo com sintomas de perda de potência sexual estavam enraizadas nos estudos psiquiátricos e a própria teoria de Krafft-Ebing é mais bem compreendida quando lida dentro desse contexto teórico.

Segundo, a necessidade de um argumento científico final para fundamentar a teoria e afastar de vez as ideias que pudessem ser traçadas a partir de pressupostos religiosos era uma preocupação de Krafft-Ebing, explicitada desde a primeira edição da obra. Com a biologia evolucionária, a partir dos trabalhos de Darwin e suas noções de instinto sexual, seleção sexual e necessidade de propagação da espécie, a ideia de perversão do instinto sexual de Krafft-Ebing pode tomar finalmente o verniz cientifico que faltava: as perversões sexuais, através de todas as suas causas e categorias, poderiam ser resumidas como o quadro no qual o instinto sexual seria pervertido de sua finalidade de evolução e preservação da espécie, de acordo com a natureza - uma natureza totalmente biológica, diferente da ideia de Natureza da Onania, que ainda era enraizada numa naturalidade de leis sobrenaturais. Nesse contexto, a medicina da sexualidade, ao mesmo tempo que abandonava noções de textos quase-médicos como a Onania, justificava, a partir de uma teoria biológica, que o instinto sexual pervertido era nocivo pois agiria contra a própria biologia e a tendência natural do ser humano para a evolução e não contra divindades e sentimentos abstratos.

O onanismo, que nunca teve seu status de ser a mais acessível, a primeira e a mais escondida das atividades sexuais improdutivas questionado, era um conceito interessante para ocupar o papel central de gatilho e aprofundamento que as degenerações e o colorido mórbido das ideias sexuais poderiam causar no sujeito predisposto às neuroses sexuais parestésicas.

Como Hare (1962, p. 9) aponta, através de Havelock Ellis é possível obter uma sumarização da visão entre os psiquiatras do final do século XIX: não era mais um debate se o onanismo causaria a insanidade, mas as autoridades médicas estariam divididas sobre sua importância nas neurastenias, incluindo as perversões sexuais. Figuras como Charcot (18251893) negavam a importância causal. Por outro lado, psiquiatras como Krafft-Ebing enfatizavam o papel da masturbação. Por isso a figura do médico Albert Moll, no contexto de teóricos da sexualidade da época, merece destaque.

Albert Moll foi um dos sexólogos mais influentes durante as três primeiras décadas do século XX. Recebeu reconhecimento dentro da comunidade médica, psicológica e psiquiátrica em 1890 com a monografia Der Hypnotismus, trabalho comentado por pioneiros da 
psicologia como William James (Siguschi, 2012, p. 185). Após a morte de Krafft-Ebing, Moll foi um dos escolhidos para continuar editando e atualizando a Psychopathia Sexualis. O autor teve um grande reconhecimento na época e suas ideias tiveram grande impacto na visão da sexualidade humana (Maehle, 2014), mas se tornou "esquecido" como teórico e mais lembrado pela sua rivalidade com Sigmund Freud (1856-1939) - causada por uma discordância sobre quem teria sido o primeiro a abordar o tema da sexualidade infantil. Mas a teoria de Moll apresenta elaborações importantes que, devido ao destaque que recebeu de seus contemporâneos, justifica o resgate histórico proposto por esse artigo.

Albert Moll tenta explicar o próprio instinto sexual para lançar as bases daquilo que viria a ser sua ideia completa sobre sexualidade infantil, apresentada em 1908. Dentro de sua explicação, o autor faz comentários acerca da masturbação - ou a estimulação voluntária e artificial dos genitais (Moll, 1908, p. 88). Portanto o conceito de libido sexual deve ser apresentado para melhor entender o caminho metodológico do autor.

Moll, em 1887, assume uma definição de instinto sexual a partir do conceito de libido sexual - conceito esse introduzido por ele dentro dos estudos da psiquiatria - para nomear a divisão daquilo que seria conhecido pelos homens como instinto sexual em dois componentes principais e relativamente independentes entre si: (a) o instinto de detumescência, o detumescenztrieb (isto é, o instinto voltado para a satisfação física), que apareceria na forma de estímulo agindo sobre os genitais e fazendo surgir a necessidade de satisfação; (b) o instinto de estimulação, o kontrektationstrieb. Esse segundo instinto teria conotações mais psicológicas, que abarcariam a ideia de sentir atração por uma pessoa como ideal de amor e a excitação em tocar, beijar e acariciar o objeto de amor para então manter relações sexuais. Ambos os instintos poderiam ocorrer separadamente em um sujeito, mas na vasta maioria dos casos ocorreriam juntos. Os dois impulsos teriam se originado ao longo da evolução humana (Simanke, 2016 p.81).

Moll (1887, p. 56) acredita que tanto o detumescenztrieb quanto o kontrektationstrieb poderiam aparecer nos indivíduos antes da puberdade, sem que isso indicasse necessariamente alguma forma de perversão sexual. Nas crianças, o instinto de detumescência apareceria desde muito cedo. Mesmo quando o kontrektationstrieb aparecesse simultaneamente ao detumescenztrieb, os dois ainda permaneceriam muito dissociados até a idade adulta, quando naturalmente se juntariam formando um só processo, a libido sexual.

A masturbação seria uma das muitas manifestações do instinto de detumescência e, por isso, poderia se manifestar como uma ocorrência puramente orgânica, sem que a imaginação tivesse nenhuma parte na realização do ato. Quando ideias fantasiosas sobre sexo 
estivessem presentes no ato da masturbação, seria pelo motivo de o instinto de estimulação estar ativo. A masturbação em crianças e adultos seria um processo muito similar. A grande diferença entre as duas etapas da vida é que a masturbação infantil seria mais independente do instinto de estimulação que a adulta, uma vez que, durante a vida adulta, ambos os instintos seriam intimamente ligados na completude da libido sexual. A masturbação infantil poderia ocorrer desde o início da primeira infância, portanto, poderia ocorrer sem a presença da ejaculação.

Essa afirmação de que a masturbação poderia ocorrer sem a presença da ejaculação é de extrema importância no contexto histórico de Moll, pois apresentou a noção de que nem todo ato masturbatório provocaria desperdício de líquido seminal.

Dentro do capítulo sobre líquido seminal, Moll define as zonas erógenas como partes da superfície do corpo que, quando estimuladas, provocariam, direta ou indiretamente, sensações voluptuosas. Além dos genitais, outras partes corpo poderiam provocar essas sensações, portanto, a masturbação também incluiria o ato de fricção ou introdução de objetos em zonas erógenas distintas dos genitais, tais como glúteos, seios, ânus e todas as outras zonas erógenas que por si só não causariam a ejaculação (Moll, 1908).

Moll passa a discutir que, dentro do contexto da masturbação, sensações sexuais de prazer ocorreriam em momentos diversos e involuntários. Para ele, seria possível observar, principalmente em crianças e adolescentes, que um sentimento de ansiedade intenso poderia ser a causa de uma excitação sexual ou até mesmo de ejaculação (com ou sem excitação sexual prévia). Nos casos que Moll atendeu ou teve conhecimento, meninos e meninas, diante de sensações estressantes, apresentavam excitação sexual involuntária e se masturbavam como forma de obter, através do relaxamento do prazer sexual, uma diminuição da sensação de ansiedade (Moll, 1908).

Mais comum que o caso descrito acima seriam as ejaculações produzidas durante o sono como resultado de sonhos eróticos. Essas manifestações seriam comuns em adultos, mas crianças também poderiam ter sensações de prazer durante sonhos eróticos. Moll (1908, p. 95, tradução nossa) especula que, ao contrário do que era comum se pensar acerca da vida sexual, o primeiro orgasmo ou a primeira ideia sexual poderia ocorrer "durante o sono com orgasmos resultados de sonhos eróticos". Uma vez que sonhos, caracteristicamente, são constantemente esquecidos quando o sujeito entra em estado de vigília, seria difícil precisar quando a primeira ideia sexual teria surgido para uma pessoa. Por esse motivo, seria possível pensar que as manifestações sexuais teriam início ainda mais cedo na vida dos seres humanos, mas sumiriam das lembranças conscientes. 
As masturbações e excitações involuntárias apresentadas na teoria de Moll causariam, invariavelmente, dentro das premissas argumentativas que o autor apresentou até aqui, uma dissonância na masturbação vista como um pecado sexual ou como uma manifestação de degeneração moral, uma vez que Moll fala de casos em que mesmo os adultos não teriam controle ou estariam completamente alheios ao ato do onanismo. O texto Onania pressupõe que, para que a masturbação em adultos fosse um ato de desrespeito à criação, seria necessária a plena consciência de que aquele ato seria contra as leis de Deus e, mesmo assim, praticá-lo. $\mathrm{O}$ ato inconsciente aproxima a masturbação de uma reação física por vezes involuntária. Sendo assim, seria possível que a masturbação ocorresse em situações nas quais seria impossível para o sujeito ter a intenção de ofender a Deus.

Essas informações sobre a masturbação, apresentadas por Moll desde o seu livro sobre a homossexualidade, levam-no a concluir, em 1908: "Mas deixe-me dizer aqui que, no início, os perigos da masturbação foram muito exagerados" (p. 180, tradução nossa). Moll (1887, 1908) argumenta que seria o esforço mental e físico empregado na obtenção da gratificação um dos elementos de causa das doenças sexuais e não os atos sexuais em si. Todo tipo de ato sexual - inclusive o ato sexual normativo - causaria um esforço e, portanto, um choque no organismo. $\mathrm{O}$ organismo que sofresse esses choques muito constantemente e em qualquer situação correria o risco de (somado a outros fatores) desenvolver doenças sexuais.

O problema identificado por Moll estaria no excesso desses estímulos, não em qual ato sexual causaria o excesso. Atos sexuais que fossem praticados em adequação aos sentimentos e à vontade, que não necessitassem de uma atividade imaginária exaustiva e que fossem praticados na ausência de estimulações corporais artificiais, seriam esforços benéficos para o organismo e um componente importante para uma vida sexual saudável. Sendo assim, as discussões deveriam mudar o foco da questão, ou seja, não mais se a masturbação seria ou não a causa para as doenças sexuais e, sim, se o esforço mental e físico empregado para alcançar a gratificação sexual através do onanismo causaria um choque maior que a relação sexual entre um par heterossexual (Moll, 1908). O problema do onanismo, para Moll, seria o fato de ser um ato sexual extremamente fácil de ser repetido de modo excessivo (tanto física quanto mentalmente) ainda em tenra idade, e não o ato em si, por isso o médico deveria desencorajar que a masturbação se tornasse um vício.

Moll continua ao longo do capítulo expressando dúvidas sobre se a masturbação causaria de fato degenerações tão extremas como as perversões sexuais. Ele acredita que a masturbação teria que estar presente dentro de um contexto bem mais específico de predisposições congênitas e do cultivo de idealizações pervertidas. Seria mais fácil pensar que 
a masturbação em excesso causasse com mais frequência alguns tipos de neurastenias mais leves, como fadiga e infertilidade, do que perversões sexuais extremas, como o sadismo e o masoquismo (Moll, 1908).

Mesmo depois de enfatizar que a masturbação em excesso seria um problema a ser observado pelos psiquiatras, o autor esclarece que seria difícil definir qual seria o limite para considerar-se excesso, devido à subjetividade dos seres humanos. $\mathrm{O}$ que poderia ser excesso para um paciente, causando grandes choques no organismo, poderia não o ser para outros. Apenas a experiência médica, as considerações sobre a subjetividade de cada sujeito e o acompanhamento do paciente poderiam dar base para afirmações sobre o papel da masturbação na vida sexual de determinado indivíduo (Moll, 1908). Por isso, a masturbação não seria um pecado ou um risco maior do que o coito heterossexual praticado com frequência desmedida ou que qualquer perversão sexual.

Por fim, Moll avalia as implicações éticas por trás do enfoque da masturbação como um hábito nocivo. O autor considera que, de fato e com fortes razões sociais éticas, tudo aquilo que causa danos ao próprio corpo ou limita a obtenção de prazer é encarado como imoral, pois depõe contra o poderoso instinto de autopreservação - exceto em casos extremos, a exemplo de um médico que se expõe ao risco de contrair uma doença para tentar salvar a vida de um paciente. Sendo assim, o excesso de masturbação poderia justificar, até mesmo de maneira inconsciente, que a prática fosse tomada como imoral, pois significaria uma queda nas chances de preservação da própria espécie humana. As razões éticas para a aversão social à masturbação poderiam ser também inconscientes, como o fato de que a masturbação seria uma atividade solitária, portanto, caso fosse moralmente aceita, a visão da importância das pessoas do outro sexo poderia ser socialmente diminuída, em especial a visão social das mulheres, "uma vez que homens seriam mais propensos a se masturbar" (Moll, 1908, p. 193195, tradução nossa).

Fosse qual fosse a razão de ordem ética e moral que a sociedade tivesse, a masturbação não poderia ser encarada de maneira muito severa por profissionais da medicina por razões também éticas. Existiriam casos em que a masturbação seria a saída de maior benefício moral para a sociedade. Por exemplo, uma pessoa com um desejo sexual incontrolável optar por ser masturbar seria moralmente superior do que procurar sexo em lugares que poderiam facilitar a contração de uma doença venérea (e depois espalhar essa doença para mais pessoas) ou optar por forçar outra pessoa a fazer sexo não consensual. $\mathrm{O}$ mesmo poderia ser dito para o caso dos paedophilos. Seria melhor que o psiquiatra se atentasse para o fato de que seria benéfico e moral para sociedade que um homem que tivesse 
desejo sexual por crianças se satisfizesse com o onanismo e apenas com pensamentos sobre uma criança do que não conseguir se controlar e consumar o ato criminoso de ferir e violentar um pequeno (Moll, 1908).

Como conclusão, Moll acredita que nenhuma relação científica determinante poderia ser feita e prefere tomar as experiências de anos de tratamentos seus e de outros: "a experiência nos mostra que quase todos os homens, saudáveis ou doentes, morais ou imorais, se masturbaram durante algum ano, algumas ou muitas vezes por semana, durante o final do segundo e início do terceiro período da infância" (Moll, 1908, p. 183, tradução nossa).

\section{Conclusão}

A história do conceito de masturbação, como apresentado, é longa na própria história da medicina e passou por muitas alterações ao longo do século XIX e início do século XX. A influência e a disseminação das ideias sobre o status que o onanismo teve para a medicina das doenças dependeu muito do sucesso das obras de autores da época e de sua posição na sociedade científica, unidos, obviamente, com o contexto social que a Europa experimentava e as transformações de teorias pelas quais passava a disciplina.

O conceito foi resistente ao longo da história da medicina, particularmente no campo da psiquiatria da sexualidade, revelando a faceta de uma disciplina que, para se firmar, esteve disposta, por um tempo, a absorver, além de famosas teorias biológicas e sociais, algumas ideias que teriam raízes divergentes do que era chamado de científico na época.

A figura de Albert Moll se mostrou importante nesse contexto. Seus trabalhos sobre a sexualidade representaram o princípio de como o paradigma da masturbação como causadora de males físicos e mentais graves foi mudando gradativamente também dentro dos estudos da sexualidade, com especial destaque para sua argumentação que descolava a masturbação de uma ocorrência exclusivamente ligada às perversões sexuais, linha argumentativa que era o foco principal das apreciações sobre o onanismo.

O presente artigo não pretende esgotar o assunto, uma vez que o conceito de masturbação ainda persistiu, mas com enfoque em seus aspectos psicológicos e em como se ligava à sexualidade como um todo, não apenas em sua faceta desviante. Nesse contexto, a criação do termo autoerotismo por Havelock Ellis e a teoria da psicanálise transformaram mais uma vez a história do conceito de onanismo. Pelas limitações de espaço, esses pontos serão tratados no artigo que constitui a segunda parte deste estudo. 


\section{Referências}

Anônimo. (1756). Onania: Or the heinous sin of self-pollution and all its frightful consequences (in both sexes). London: H. Cooke. (Obra original publicada em 1716)

Beard, G. (1869). Neurasthenia, or nervous exhaustion. Boston Medical and Surgical Journal, 1(80), 217-221. doi: 10.1097/NMD.0000000000000938

Blashfield, R. K. (2019). Pre-Kraepelin Names for Mental Disorders. The Journal of Nervous and Mental Disease, 207(9), 726-730. doi: 10.1097/nmd.0000000000000938

Ellis, H. (1898). Auto-Erotism. Alienist and Neurologist, 19, 260-299.

Garlick, S. (2011). Masculinity, Pornography, and the History of Masturbation. Sexuality \& Culture, 16(3), 306-320. doi: 10.1007/s12119-011-9125-y

Hall, L. A. (1992). Forbidden by God, despised by men: Masturbation, medical warnings, moral panic, and manhood in Great Britain, 1850-1950. Journal of the History of Sexuality, 2(3), 365-387.

Hare, E. H. (1962). Masturbatory Insanity: The History of an Idea. Journal of Mental Science, 108(452), 1-25.

Hermle, L. (1986). Die Degenerationslehre in der Psychiatrie. Fortschritte Der Neurologie und Psychiatrie, 54(3), 69-79.

Hunt, A. (1998). The great masturbation panic and the discourses of moral regulation in nineteenth- and early twentieth-century Britain. Journal of the History of Sexuality, 8(4), 575-615. Recuperado de http://www.jstor.org/stable/3840411

Kaan, H. (1844). Psychopathia Sexualis. Nova York: Leopoldo Voss.

Krafft-Ebing, R. (1894). Psychopathia Sexualis. (7a ed.). Stuttgart: Enke.

Laqueur, T. (2003). Solitary sex: A cultural history of masturbation. New York: Zone Books.

Maehle A. H. (2014). The powers of suggestion: Albert Moll and the debate on hypnosis. History Psychiatry, 25(1), 3-19. doi: 10.1177/0957154X13500596

Maudsley, H. (1867). The physiology and pathology of the mind. New York: Appleton.

Moll, A. (1887). Untersuchungen über die libido sexualis. Berlin: H. Kornfeld.

Moll, A. (1908). Das Sexualleben des Kindes. Leipzieg: Verlag Von F.C.W Volgel.

Sigusch, V. (2012). The sexologist Albert Moll-between Sigmund Freud and Magnus Hirschfeld. Medical history, 56(2), 184-200. doi: 10.1017/mdh.2011.32

Simanke, R. T. (2016). Freud e a sexualidade infantil antes de Freud. In J. Birman, L. Fulgêncio, E. Leal, \& D. Kupermann (Eds.), Amar a si mesmo e amar o outro: 
Narcisismo e sexualidade na psicanálise contemporânea (pp. 43-63). São Paulo: Zagodoni.

Simião, A.R.M (2019). Instinto e Objeto Sexual nas teorias de Krafft-Ebing, Moll e Freud (Tese de Doutorado). Universidade Federal de Juiz de Fora, Juiz de Fora.

Stolberg, M. (2000). Self-Pollution, moral reform, and the veneral trade: Notes on the source and historical context of Onania (1716). Journal of History of Sexuality, 9(1-2), 37-61. Recuperado de http://www.jstor.org/stable/3704631

Tissot, A. D. S. (1769). L'onanisme: Dissertation sur les maladies produites par la masturbation. Lausanne: M. Chapilo. (Obra original publicada em 1756)

Weeks, J. (1985). Sexuality and its discontents: Meanings, myths \& modern sexualities. London: Routlegde \& Kegan Paul.

\section{Endereço para correspondência}

\section{Anna Rita Maciel Simião}

Rua Santo Antonio, 1063, 204, Centro, Juiz de Fora - MG, Brasil. CEP 36016-210

Endereço eletrônico: anna_rmsimiao@yahoo.com.br

\section{Richard Theisen Simanke}

Rua Leonildo Gonçalves Regado, 214, 8, Parque Ato, Juiz de Fora - MG, Brasil. CEP 36038-420

Endereço eletrônico: richardsimanke@uol.com.br

Recebido em: 21/10/2020

Reformulado em: 02/12/2020

Aceito em: 04/01/2021

\section{Notas}

* Psicóloga, graduada pela Universidade Federal de Juiz de Fora, doutoranda pela Universidade Federal de Juiz de Fora.

** Professor Titular do departamento de Psicologia da Universidade Federal de Juiz de Fora.

${ }^{1}$ O termo autoerotismo, cunhado por Havelock Ellis em 1898, foi definido como se referindo aos fenômenos da emoção sexual que fossem espontâneos e gerados na ausência de um processo de estímulo externo a partir de outra pessoa. As manifestações autoeróticas incluiriam algumas manifestações da atividade sexual reprimida, tais como o onanismo, que estariam presentes em algumas condições mórbidas, mas também fariam parte das tendências normais da sexualidade e, em certa medida, influenciariam toda a vida sexual de um sujeito.

${ }^{2}$ Para melhor fluidez do texto, o autor desconhecido do livro Onania será referenciado nesse artigo como Anônimo. 
3 Em inglês, existia ainda o termo self-pollution, usado, na maior parte dos casos, como sinônimo de masturbação e onanismo. Esse artigo seguirá a mesma linha e irá traduzir o termo por onanismo.

${ }^{4}$ As muitas edições da Onania não tiveram grandes variações de esquema. As maiores alterações consistiam em mais relatos e cartas de onanistas para o autor. Nos textos consultados para compor a bibliografia deste artigo, não existe consenso sobre um número exato de edições da Onania, mas entre as edições consultadas durante o estudo que deu origem a esta pesquisa identificamos que o livro foi editado pelo menos até uma décima sétima versão, datada de 1752 .

${ }^{5}$ Hare (1962) aponta Onania Examine or Detected de Philo Catiatus como um livro totalmente dedicado a criticar a Onania, mas ressalta que historicamente o livro não causou grande impacto e influência.

${ }^{6}$ A imbecilidade, junto com a idiotia, eram conceitos comuns no século XIX (Blashfiels, 2019). A idiotia era a deficiência mental causada por desnutrição ou doença dos centros nervosos, ocorrendo antes do nascimento ou antes da evolução das faculdades mentais na infância.

${ }^{7}$ Ao usar o termo degeneração nos indivíduos, os autores aqui citados estavam fazendo referência à teoria da degeneração, um conceito geral, idealizado por Benédict Morel (1809-1873) por volta de 1850, com raízes e influências na biologia, na medicina e nas ciências sociais para indicar uma teoria de regressão humana, em suas capacidades biológicas, fisiológicas, sociais e mentais, manifestada por sinais degenerativos em indivíduos. Foi um fator importante na medicina e especialmente na psiquiatria durante a segunda metade do século XIX e no início do século XX (Hermle, 1986, p. 69).

${ }^{8}$ Essa é a tradução literal do latim, idioma da obra. Kaan está se referindo à relação sexual com crianças. Em 1844 o termo pedofilia ainda não existia para designar o ato de pessoas que abusassem sexualmente de crianças, então outras expressões eram comuns. Paedophilia erotica, a pedofilia, foi um termo cunhado em 1896 por Richard von Krafft-Ebing.

Financiamento: a pesquisa relatada no manuscrito foi financiada pela bolsa de mestrado/doutorado da primeira autora, bolsa CAPES (processo: 88881.135059/2016/01).

Agradecimento: os autores agradecem à Universidade de Durham (Inglaterra, Reino Unido) e aos professores Dr. Andreas Holger Maehle e Dr. Lutz Sauerteig pela disponibilização de espaço e de material e pelas discussões que possibilitaram essa pesquisa.

Este artigo de revista Estudos e Pesquisas em Psicologia é licenciado sob uma Licença Creative Commons Atribuição-Não Comercial 3.0 Não Adaptada. 